\title{
OPERATION OF MILITARY EQUIPMENT AND UTILIZATION OF NEW PEDAGOGICAL APPROACHES TO IMPROVE THE EFFICIENCY IN THE EDUCATIONAL PROCESS
}

\author{
Jaromir MARES, Vaclav ZAJICEK, Aly Hawa CAMARA, \\ Katerina POCHOBRADSKA \\ University of Defence, Brno, Czech Republic, \\ jaromir.mares@unob.cz, vaclav.zajicek@unob.cz, aly.camara@unob.cz, \\ katerina.pochobradska@unob.cz
}

\begin{abstract}
The paper deals with the enhancement efficiency of pedagogical procedures of military equipment operation. The aim of the paper is to point out how there were created selected sequences of logistics processes implemented in the use and maintenance, including information support for available analytical tools. There were also redefined logistics processes to understand management functions and logistics processes. As a result of the research a software was developed, which by basic analogous methods and programming helps to develop the educational e-learning program. The program is applicable in the Moodle environment for the needs of students. The educational program aims at verifying the knowledge acquired in the area of operation and its objective is to support practicing principles and procedures. The program is based on a methodical practice of selected activities. It was created for practicing in the e-learning environment. The course has multifunctional purpose, especially to introduce to students selected processes logistical support. The course has to evaluate through interactive approaches, to verify theoretical and practical knowledge. It should help to teach the students how to work in logistics information system (ISL) environment and deepen their practical skills.
\end{abstract}

Keywords: simulation of logistics processes, operation of equipment and materials, e-learning programs, Moodle

\section{Introduction}

Logistics processes and their simulation are an important element for creating models of individual tasks and processes. It is an important tool and asset for practical contribution, solutions and scientific approaches.

Theoretical basis of this project has a holistic approach, i.e. a complex of logistical processes among themselves do not have hierarchical character but through mutually provided activities which have network relation.

To increase the effectiveness of the educational process in recent years, there are used and constantly improving various teaching methods and especially support educational programs. E-learning programs are increasingly used in various forms. Due to the requirements in logistics, it is essential to enhance the quality and preparation of graduates. It is required to connect theoretical instruction and practice with the troops. For this reason, it seemed appropriate to create an e-learning vocational course applied in Moodle for the use in classes of the equipment operation. Presented variations of tasks within a 
course were focused on practical management of selected logistics activities focused on the ACR (Army of Czech Republic) formations.

\section{Current status of topic}

Educational programs began to be used at various stages in the eighties. It was possible to see it at various schools both technical and humanitarian. They were created originally as try-out tasks of different kinds through the paper version, such as test questions. For simplicity of correcting there were created united formats and for evaluating there were used evaluation templates that allow teachers to increase speed in the correction process. Later it has started to create a combination of a written test with questions, but with the machine evaluation. As a modern way, it has begun to combine word entry with the test answers inserted into the evaluation machine using the corresponding buttons. For other forms of testing, computer-aided testing programs are developed and applied.

From e-learning programs there are used programs like Barborka and Moodle, which are currently used at the University of Defence in Brno. With the use of Moodle, each of its departments has its own teaching experience and tradition. Used tests are gradually improving from amateur attempts to fine, almost professional finish. In the ACR - the University of Defence uses Moodle programs for testing students who must pass a test in a certain time. It is also possible to define the time when the student must sit at the computer and complete the test.

In Moodle it is possible to study a variety of support materials and testing materials that teachers are posting there. Based on long-term cooperation, they are aware of information from foreign colleagues from the partner armies. This mainly concerns the Austrian army, where there are created tests in Moodle and the US military where they are carrying out various forms of professional tests, including computerized testing at language schools.
The paper is focusing on the results obtained from the project in several phases. In the first phase, the sequence of logistic processes implemented at the military unit operation of GME (ground military equipment). The focus for the solution is the use and maintenance of vehicles. This is the focus of including information support with available analytical tools.

The aim of the solution is to analyse, describe and to design selection of comprehensive logistics processes running at tactical level by creating original practice program (e-learning) in environment of LIS (Logistics Information System) for the students' preparation at the University of Defence.

The idea is to secure the streamlining of logistical tasks in organizational element at tactical level of the Ministry of Defence (MOD). Process analysis includes a series of activities which must be performed by logistician to fulfil the tasks or achieved procedural goal. These activities are, in practice, on the one hand supported by extensive data base and rich functionality of Logistics Information System (ISL) and, on the other hand, they are also performed manually.

Training application includes an algorithm to solve the task of logistics practice at the department. The application is supposed to allow the user to relevantly respond to requests and feedback on the performance of the training task. The effect of application is expected in eliminating errors, speeding up the activity and increasing the effective activity of the individual in a real environment troop practice. [1], [2], [3], [4, [5].

In real practice of knowledge management and knowledge transfer presupposes and requires a comprehensive understanding of: logistics processes; internal regulations; organizational relationships and their synergies; methodology of work and safety at work; using established information technology; use of practical experience and knowledge 
(Lessons Learned) in the field of logistics information systems and their mastery of practical application.

With regard to changing external and internal environment of the Czech Ministry of Defence and social development in the creation and transfer of knowledge for individuals in practice, it is a necessity to constantly improve the use of data bases and functionality of ISL in the entire management cycle.

The pilot training course is designed to guide the lessons of logistical supporting process. The software allows real testing of animation at training areas ISL. Speed of training is individual. [6], [7], [8], [9], [10].

\section{Goals, methods and restrictions for creating the e-learning program}

The aim was to support the training of military professionals with a focus on complex logistic processes.

It was determined to create the sequences of selected logistics processes implemented in operation - use and maintenance on the unit, including information support with available analytical tools. Logistics processes were defined to understand management functions and logistics processes. There were to set goals for students - to check knowledge gained about the operation, practicing policies and procedures, methodically to practice the selected activities, effectively to learn to acquire new knowledge.

Among others, in this professional course the aim is to introduce to students selected processes of logistic support, to examine through the form of interactive approaches with verification of theoretical expertise, to teach the students how to work in an environment of LIS and to deepen their knowledge in the practical application of LIS in education support.

For the course e-learning methods have been used associated with programming, which is necessary for application in the LIS.

Due to the significant scope of operation issues armaments and equipment need to be taken into account in creating a pilot study course with certain limits and restrictions: for content SW-MSPL there were selected processes of planning and management and maintenance of military equipment to the ground tactical level; selected activities will be carried out according to the instructions and guidance of teachers (LIS need to connect CADS); within the SW-MSPL there will not be solved some of the activities related to synergies with other organizational units of the ACR and not directly related to the issues set for the stage of SW-MSPL.

\section{Results, discussion and proposals}

One of the published outputs of the project is the methodology for solving problems during the use of e-learning programs under operation in ACR. For this purpose, strong database of tasks were developed.

The outcome of the project is the methodology which is created mainly to test the usability for the classes. In this way there was developed the course useful for classes of technical preparation, the course for testing students in the operation of military vehicles. The course can be realized only under conditions of possibility of access to a specialized network with access to Moodle. Another option is to use all-army networks with access to the LIS. In any case, you can work independently within a limited time under the guidance of a professionally equipped specialist or teacher, and some tasks can be accomplished without them. [11], [12].

\subsection{Simulation modules}

The course is divided into four simulation modules (SM), which are the following:

SM 1 - System of operation of ground military techniques in the ACR.

SM 2 - Planning of operation and maintenance of military equipment for ground military unit.

SM 3 - Operational management and maintenance of military equipment for 
ground military unit.

SM 4 - Evaluation of the use and maintenance of military equipment for ground military unit

SM 1 - Simulation Module 1: The system of operation ground military equipment (PVT) in ACR allows a student to show by text or image file information from the system of operation and maintenance of ground-based military technology.

SM 2 - Simulation Module 2: Planning the operation and maintenance of ground military technology at the department allows to simulate processing of prospective plan, annual operation plan, annual maintenance plan, operational plan of operation and operational maintenance plan.

SM 3 - Simulation Module 3: Management of operation and maintenance of military equipment for ground military unit allows to simulate the process by using a weekly schedule, the command to use techniques, planning and maintenance, data entry operation and maintenance to LIS.

SM 4 - Simulation Module 4:
Evaluation of operation and maintenance of military equipment at ground military unit allows to simulate the processing of monthly report of operation S01, S05 operating status, overconsumption, control of reserves in maintenance, evaluation of the annual operation plan and annual maintenance plan within the specified range. [13], [14], [15].

\subsection{An entrance test and idea of the course}

Virtual model of organization ACR is ready for issue, "Planning and management of operations and maintenance at the level of battalion (tactical level)."

The simulation is divided into a total of 6 classes, see Table 1, that followed mentioned content distribution is only indicative and in practice it will be subject to individual abilities of individual students and the entire teaching groups.

The final test, the overall evaluation and possibility of setting the individual tasks for students who failed, will be performed during the active participation of the teacher.

Table 1 Time schedule of the test

\begin{tabular}{|c|c|c|}
\hline $\begin{array}{l}\text { Lessons } \\
\text { (Educational } \\
\text { Block) }\end{array}$ & The content of the lesson - stated generally & Notes \\
\hline $1-2$ & $\begin{array}{l}\text { Starting the course by lector, preparing the } \\
\text { workplaces, entrance briefing and completing of } \\
\text { the entrance test }\end{array}$ & \\
\hline $3-4$ & $\begin{array}{l}\text { Methodological procedure with the practical } \\
\text { implementation of the specified processes } \\
\text { (simulation module) }\end{array}$ & $\begin{array}{l}\text { Starts after first and second } \\
\text { lesson, and can be modified }\end{array}$ \\
\hline $5-6$ & Individual work (consultation) of the students & $\begin{array}{l}\text { Processes are flexible } \\
\text { according to the needs of } \\
\text { teachers }\end{array}$ \\
\hline
\end{tabular}

\section{Entrance test}

Each student must initiate the course with an entrance test: The aim of the entry test is to test students' knowledge and certain skills that are essential for the successful management of the main contents SW-MSLP.

The content of test is organized into sets of 45 questions with prepared three answers for each question. Each set of 
questions is divided into 3 blocks, which correspond to the three thematic topics of the defined military and specialized issues.

If, at the first trial, the necessary evaluation criteria will not be accomplished, the same test can no longer be repeated again. The student will be given a new test where variants of questions and answers in the test will be changed.

While repeating the entrance test will be accessible database of study materials (to have access to the transcripts, professional standards and regulations, scripts, etc.). So, each student is allowed to study relevant information and the test is successfully completed.

Evaluation criteria of success for fulfilling the entry test: The test consists of 30 accidentally generated questions. For successful completion of the test, the student must answer all the questions correctly. If this criterion is not met, it will not be able to move to the main part of the course. Each of the students will have two attempts for completing the entrance test.

\subsection{Inputs to the individual simulation modules}

Simulation modules are interconnected and continuously follow each other. Each module ends with a key question(s) that in the case of the correct answer enables access to the next module. If the answer to the key question(s) will be wrong, students must go back to the introduction module and re-read the whole issue of the module. There are two attempts to handle the questions. Each module is complemented by a graphical representation of a process, model documents that relate to a given process and optionally with animation. Animations illustrate the technological process to solve practical activities in the ISL. To meet the selected parts of the module is required to perform selected operations in the LIS. To this fact, the student is warned by the teacher and it is stated in the text of methodical procedure. An activity that is carried out in the ISL is necessary to read through theory and practice by using the set of animations. Subsequently, the student goes to the computer that is connected to the all-army data network under user name and password to login. Connection is made in a standard manner as in the system of the LIS. The teacher is assigning a login (stud11 stud20) and giving the password to log into the test database of virtual units.

The teacher works on a central server and a local server and is coordinating the activities. Students work individually on a local server database of selected virtual military unit (VIRT11-20) based on the teacher's instructions. As a user of this virtual military department, the student has predefined user groups. These user groups allow students to work in selected subsystems of LIS - evidence of material and Maintenance of VT. In these modules the student works as a real user in a real environment LIS, but on the model of organization and ACR tests data.

\subsection{The output of each module}

The output of each module is summary of the issues of the module. Furthermore, there are the processed tasks and control questions to think about. Each simulation module is completed by a key issue, which (if correct answers) exposes the following simulation module.

\section{Conclusion}

Simulation of logistics processes is a modern tool for analysing complex acquisition, supply, maintenance, communication and other processes of ACR.

Simulation is a method that by a computer-based model of the logistics process allows to predict system behaviour during changing the internal and the external conditions. Next, it is to optimize logistics processes with respect to specified criteria (quality, reliability, speed of delivery) and to compare the proposed alternative organization of studied process.

A considerable advantage of simulation is that everything happens only 
in a virtual, electronic model, without any intervention into the operation of logistics of ACR. Using simulation, it is possible to explore various alternatives to the changes in the system, to test the effects and consequences of these changes and choose a solution that best suits the situation. The risk of incorrect decisions through simulation of models is greatly reduced because the error which has been discovered in the simulation in virtual model is always cheaper than the error that is discovered after the implementation of the logistic process in practice.

\section{References}

[1] ČSN EN ISO 9001:2009. The Quality of Management System

[2] ČSN ISO/IEC 12207. Information technology-Processes in the life cycle software.

[3] User book for Planning of Maintenance, ID: ISL-UVT-DUM 001/08, revision 1.4.

[4] User book for Planning of Maintenance - extension of the operational operation of control ID: ISL UVT-DUM 001/00, revision 3.0;

[5] User book for Maintenance and check. ID: ISL-UVT-DUU 001/01, review 2.1.

[6] AURA-TQM-QQG 001 / 99 Book of quality, AURA, s.r.o.

[7] AURA-SW-QQG 600/99. Evaluation, verification and authorization.

[8] DLOUHÝ, M., FÁBRY, J., KUNCOVÁ, M., a HLADÍK, T., Simulation of factory processes; Computer press, Brno, 2007. ISBN 978-80-251-1649-4.

[9] DRLÍK, M., SVEC, P., KAPUSTA, J. a MESÁROŠOVÁ M., Moodle, Modern guide creating and management of electronic courses, Computer press, Brno, 2013. ISBN 97880-251-3759-8.

[10] Rienhaus, D. Learning techniques. How to learn easier and remember more. Grada, Praha, 2013. ISBN 978-80-247-4781-1.

[11] KOPECKY, K., E-learning (not only) for pedagogues. Hanex, 2005. ISBN 80-85783-509.

[12] ŘEPA, V. Procedurally managed organization, Management in the Information Society.Grada, Praha, 2012, 978-80-247-4128-4.

[13] Vseob P-37; Rules of vehicles operation in military.

[14] Guidelines for the use of ground military equipment in ACR in peace, (č.j:62722/2006/DP-3042).

[15] Order of MOD No. 48/2013; The management and dealing with property of the Ministry. 